\title{
Correlation between ionic conductivity and fluidity of polymer gel electrolytes containing $\mathrm{NH}_{4} \mathrm{CF}_{3} \mathrm{SO}_{3}$
}

\author{
HARINDER PAL SINGH, RAJIV KUMAR and S S SEKHON* \\ Department of Applied Physics, Guru Nanak Dev University, Amritsar 143 005, India
}

MS received 21 April 2004

\begin{abstract}
Nonaqueous polymer gel electrolytes containing ammonium triflate $\left(\mathrm{NH}_{4} \mathrm{CF}_{3} \mathrm{SO}_{3}\right)$ and dimethylacetamide (DMA) with polymethylmethacrylate (PMMA) as the gelling polymer have been synthesized which show high value of conductivity $\left(\sim \mathbf{1 0}^{-2} \mathrm{~S} / \mathrm{cm}\right)$ at $25^{\circ} \mathrm{C}$. The conductivity of polymer gel electrolytes containing different concentrations of $\mathrm{NH}_{4} \mathrm{CF}_{3} \mathrm{SO}_{3}$ shows a small decrease with the addition of PMMA and this has been correlated with the variation of fluidity of these gel electrolytes. The small decrease in conductivity with PMMA addition shows that polymer plays the role of stiffener and this is supported by FTIR results which also indicates the absence of any active interaction between polymer and $\mathrm{NH}_{4} \mathrm{CF}_{3} \mathrm{SO}_{3}$ in these gel electrolytes.
\end{abstract}

Keywords. Ionic conductivity; ion aggregates; FTIR spectroscopy; gels; fluidity.

\section{Introduction}

Proton conducting polymer electrolytes are materials of current interest due to their possible use in proton exchange membrane fuel cells (PEMFC), display devices, supercapacitors etc (Colomban 1992; Laforgue et al 1999; Cronin et al 1999; Paoli et al 2001; Perry and Fuller 2002). Solvent free polymer electrolytes based on the complexation of high molecular weight polyethylene oxide (PEO) and polypropylene oxide (PPO) with various ammonium salts have been studied in detail (Daniel et al 1988; Chandra et al 1990; Prusinowska et al 1994; Oradd et al 2000; Kumar and Sekhon 2002). Polymer electrolytes obtained by the complexation of ammonium triflate $\left(\mathrm{NH}_{4} \mathrm{CF}_{3} \mathrm{SO}_{3}\right)$ with PEO and PPO were also reported (Stainer et al 1984; Ansari et al 1985) in early eighties but due to their lower conductivity they were not persued thereafter.

Polymer gel electrolytes are another category of polymer electrolytes in which the solvent is retained in the electrolyte and these show high value of conductivity approaching $10^{-2} \mathrm{~S} / \mathrm{cm}$ at room temperature. These electrolytes belong to solvent-salt-polymer hybrid system in which the salt solution is immobilized by the addition of a suitable polymer matrix (Feuillade and Perche 1975; Tsuchida et al 1983; Abraham and Alamgir 1990). The solvent provides the conducting medium whereas polymer provides mechanical stability to these electrolytes (Webber 1991; Sekhon et al 1998). The membrane presently being used in PEMFC is very expensive and as its conductivity depends upon humidity level, it can be used

*Author for correspondence (sekhon_apd@yahoo.com) over a limited range of temperature only (Slade et al 1983). Due to this there is a growing need for developing an alternative proton conducting membrane which possess high value of conductivity and is also suitable for use over a wide temperature range. This is the motivation for the present work.

In the present paper, polymer gel electrolytes containing $\mathrm{NH}_{4} \mathrm{CF}_{3} \mathrm{SO}_{3}$ in dimethylacetamide (DMA) and with polymethylmethacrylate (PMMA) as the gelling polymer have been studied. Conductivity, $\mathrm{pH}$ and viscosity of liquid and polymer gel electrolytes have been studied as functions of salt concentration, polymer concentration and temperature. FTIR studies have also been carried out to check the interaction between salt, solvent and polymer.

\section{Experimental}

Ammonium trifluoromethanesulphonate $\left(\mathrm{NH}_{4} \mathrm{CF}_{3} \mathrm{SO}_{3}\right)$ (Aldrich), dimethyl-acetamide (DMA) (dielectric constant $=37 \cdot 8$, viscosity $=1.937 \mathrm{cP}$ at $25^{\circ} \mathrm{C}$ ) (Merck) and polymethylmethacrylate (PMMA) (Aldrich, av. mol. wt. $120,000)$ have been used as the starting materials in the preparation of liquid and gel electrolytes. Liquid electrolytes were prepared by dissolving $\mathrm{NH}_{4} \mathrm{CF}_{3} \mathrm{SO}_{3}$ in different concentrations (expressed as molarity value) in DMA and then gel electrolytes were obtained by adding PMMA in different amounts (expressed as wt\% of liquid electrolyte) to the liquid electrolytes along with continuous stirring. The conductivity was measured by complex impedance spectroscopy using HP4284A precision LCR meter in the $20 \mathrm{~Hz}-1 \mathrm{MHz}$ frequency range with a cell using platinum electrodes, details of which have been published earlier (Sekhon et al 1998). The viscosity of electrolytes was measured by Fungilab rotating viscometer model Visco 
Basic L and $\mathrm{pH}$ was measured by Systronics $\mathrm{pH}$ meter model 335. Room temperature FTIR spectra of all the samples was recorded in the $400-4000 \mathrm{~cm}^{-1}$ range by Perkin Elmer FTIR spectrometer.

\section{Results and discussion}

The electrical conductivity of liquid electrolytes prepared by adding $\mathrm{NH}_{4} \mathrm{CF}_{3} \mathrm{SO}_{3}$ in different concentrations to DMA was measured and the variation of conductivity with salt concentration is given in figure 1. At low salt concentrations, the conductivity increases linearly and the conductivity of solvent $\left(\sim 10^{-6} \mathrm{~S} / \mathrm{cm}\right)$ has been found to increase by four orders of magnitude to a value of $\sim 10^{-2} \mathrm{~S} / \mathrm{cm}$ even at low concentration $(0 \cdot 1 \mathrm{M})$ of salt. $\mathrm{NH}_{4} \mathrm{CF}_{3} \mathrm{SO}_{3}$ upon dissociation in solvent with high dielectric constant provides free ions, which take part in the conduction process and as a result conductivity increases. With further increase in salt concentration, conductivity reaches a maximum value of $3.65 \times 10^{-2} \mathrm{~S} / \mathrm{cm}$ and then shows a small decrease at higher salt concentrations. The decrease in conductivity at higher salt concentrations is due to the presence of ion aggregates which do not take part in the conduction process, along with an increase in viscosity which would also result in lower conductivity (Bohnke et al 1993a; Southall et al 1996). The viscosity of electrolytes was also measured and its variation with the concentration of $\mathrm{NH}_{4} \mathrm{CF}_{3} \mathrm{SO}_{3}$ is given in figure 2. The viscosity increases with an increase in salt concentration although the increase is very small. However, distinction must be made between macro and micro viscosity, the

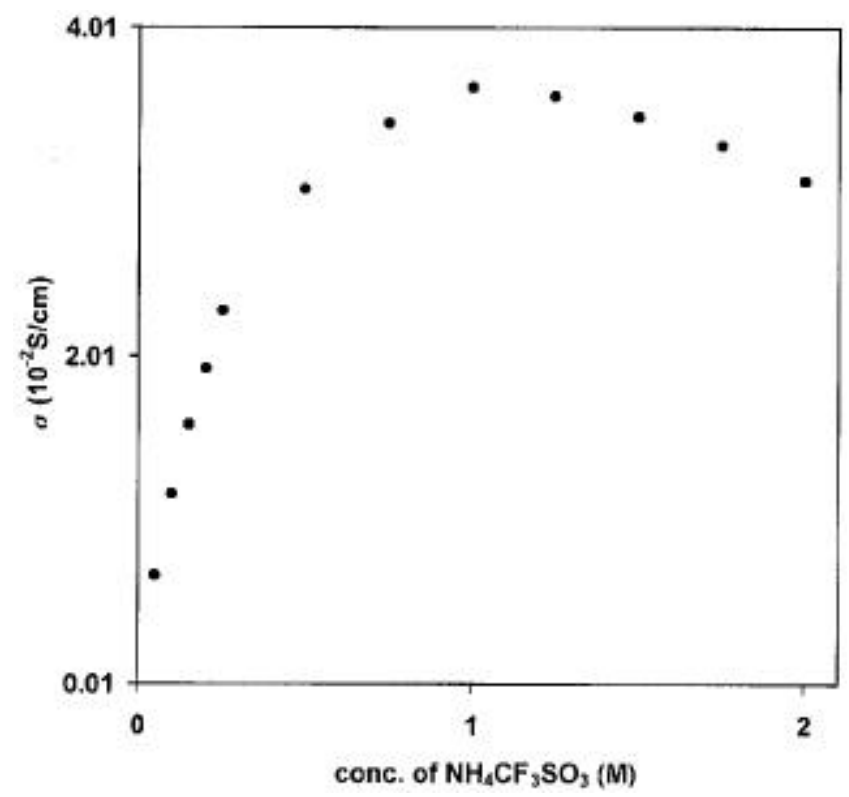

Figure 1. Variation of conductivity $(\sigma)$ of liquid electrolytes as a function of $\mathrm{NH}_{4} \mathrm{CF}_{3} \mathrm{SO}_{3}$ concentration. viscosity measured experimentally is macroscopic in nature whereas it is the microscopic viscosity which is inversely related to mobility and hence conductivity (Bohnke et al 1993b).

The formation of ion aggregates at higher salt concentrations was also checked by mass action considerations (Ratner 1987). According to this method, if all the ions are present as free ions, then the plot between $\log \sigma$ and $\log C$ (where $\sigma$ and $C$ are the conductivity and concentration of salt in the electrolyte, respectively) shall be a straight line and if ion aggregates are formed then the plot between $\log \sigma$ and $\log C$ shall show a deviation from straight line behaviour. A graph plotted between $\log \sigma$ and $\log C$ for liquid electrolytes containing $\mathrm{NH}_{4} \mathrm{CF}_{3} \mathrm{SO}_{3}$ in DMA is given in figure 3. At low salt concentrations the plot shows a straight-line behaviour whereas at high salt concentrations it shows deviation from straight line behaviour and the deviation increases with an increase in salt concentration. This suggests the presence of ion aggregates at higher salt concentrations, which is in agreement with the conductivity results given in figure 1.

The dissociation of $\mathrm{NH}_{4} \mathrm{CF}_{3} \mathrm{SO}_{3}$ in the solvent shall give rise to free $\mathrm{NH}_{4}^{+} / \mathrm{H}^{+}$ions and their concentration shall vary with a change in salt concentration. As the $\mathrm{pH}$ of an aqueous solution depends upon the concentration of free $\mathrm{H}^{+}$ions $\left[\mathrm{pH}=-\log \left(\mathrm{H}^{+}\right.\right.$(aq.) $)$] so any change in $\mathrm{H}^{+}$ ion concentration shall be reflected in the $\mathrm{pH}$ of the electrolyte. $\mathrm{pH}$ of liquid electrolytes was, therefore, measured as a function of $\mathrm{NH}_{4} \mathrm{CF}_{3} \mathrm{SO}_{3}$ concentration and the results are given in figure 4 . For comparison the variation of $\log$ conductivity with salt concentration is also included in figure 4 . The $\mathrm{pH}$ of liquid electrolytes decreases sharply

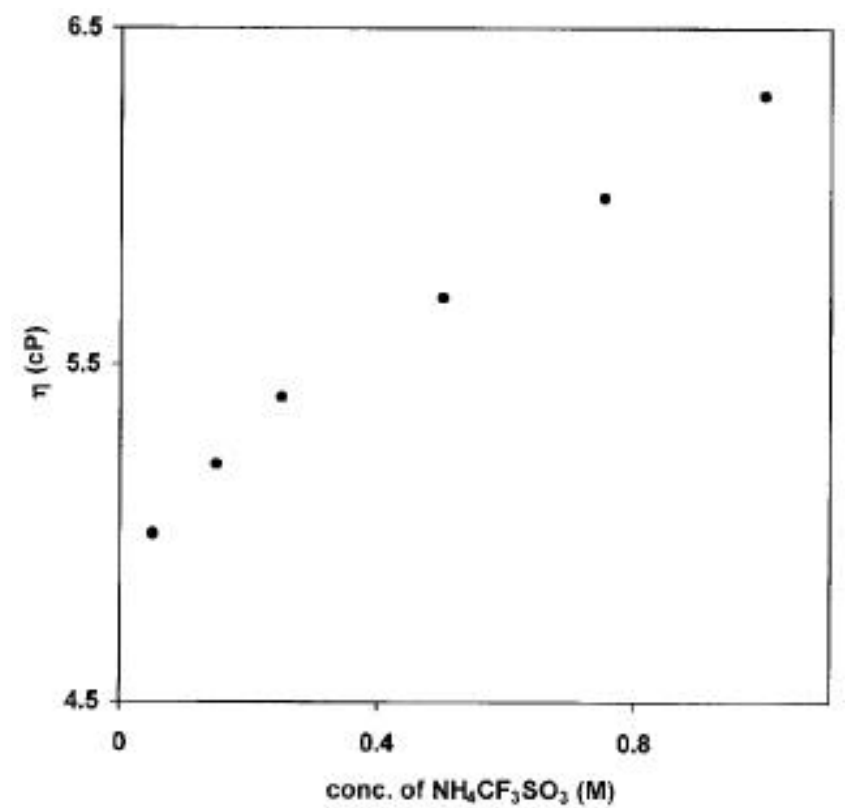

Figure 2. Variation of viscosity $(\eta)$ of liquid electrolytes as a function of $\mathrm{NH}_{4} \mathrm{CF}_{3} \mathrm{SO}_{3}$ concentration. 
with the addition of even a small amount (0.1 M) of $\mathrm{NH}_{4} \mathrm{CF}_{3} \mathrm{SO}_{3}$ which indicates that free ions are provided by the salt. With further increase in salt concentration, $\mathrm{pH}$ decreases slowly and reaches a nearly saturation value at higher salt concentrations up to $2 \mathrm{M}$. The small change in $\mathrm{pH}$ at higher salt concentrations indicates that $\mathrm{H}^{+}$ions provided by the salt are not free and may result in the formation of ion aggregates. These results are also in agreement with the conductivity variation which also increases from $10^{-6} \mathrm{~S} / \mathrm{cm}$ to $10^{-2} \mathrm{~S} / \mathrm{cm}$ with the addition of $\mathrm{NH}_{4} \mathrm{CF}_{3} \mathrm{SO}_{3}$ and thereafter reaches a near saturation value which suggests that no new free $\mathrm{H}^{+}$ions are available for conduction and $\mathrm{H}^{+}$ions provided by an increase in salt concentration are used in the formation of ion aggregates. These results are consistent with the results of mass action considerations as given in figure 3 .

The electrical conductivity of polymer gel electrolytes obtained by the addition of PMMA to liquid electrolytes was measured as a function of PMMA concentration and the results are given in figure 5. As the formation of ion aggregates depends upon salt concentration so liquid electrolytes containing different levels of ion aggregation i.e. different concentrations of $\mathrm{NH}_{4} \mathrm{CF}_{3} \mathrm{SO}_{3}(0 \cdot 1,0 \cdot 25,0 \cdot 5$, 0.75 and $1 \mathrm{M}$ ), were used in the preparation of gel electrolytes. The results of figure 5 show that conductivity of liquid electrolytes containing different concentrations of $\mathrm{NH}_{4} \mathrm{CF}_{3} \mathrm{SO}_{3}$ decreases with an increase in PMMA content but the decrease is small and is by a factor and not by an order. The conductivity of polymer gel electrolytes containing 4 and $10 \mathrm{wt} \%$ PMMA was also measured as a function of salt concentration and the results are given in figure 6. For comparison the variation of conductivity with salt concentration for liquid electrolyte is also in-

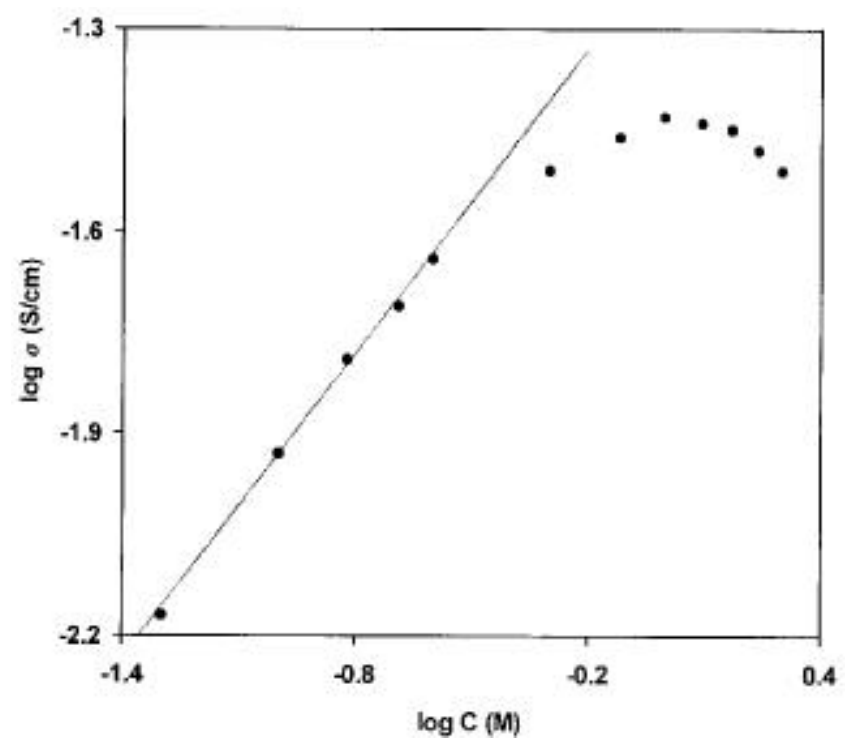

Figure 3. Log conductivity vs log salt concentration plot for liquid electrolytes containing $\mathrm{NH}_{4} \mathrm{CF}_{3} \mathrm{SO}_{3}$ in DMA. cluded in this figure. The results show that conductivity of gel electrolytes is lower than the corresponding liquid electrolytes at all salt concentrations but the difference is very small and is by a factor only. The small change in conductivity observed with the addition of PMMA as given in figures 5 and 6 suggests that the polymer does not play an active role in the conduction process and acts as a stiffener only (Sekhon et al 1998).

As the addition of polymer provides dimensional stability to the electrolytes by increasing its viscosity so the

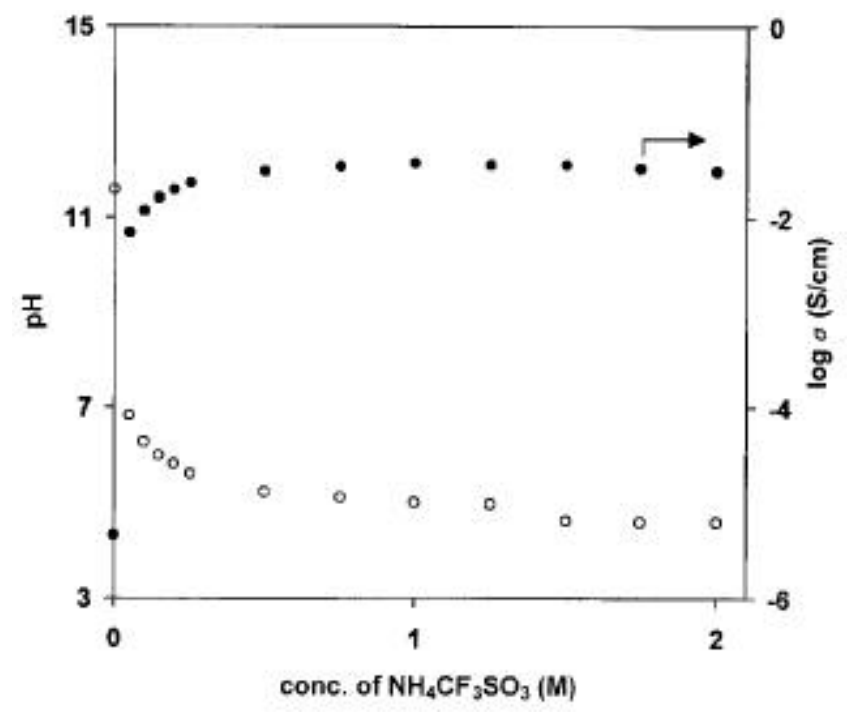

Figure 4. $\mathrm{pH}(\mathrm{o})$ and $\log$ conductivity $(\bullet)$ variation for liquid electrolytes with $\mathrm{NH}_{4} \mathrm{CF}_{3} \mathrm{SO}_{3}$ concentration in DMA.

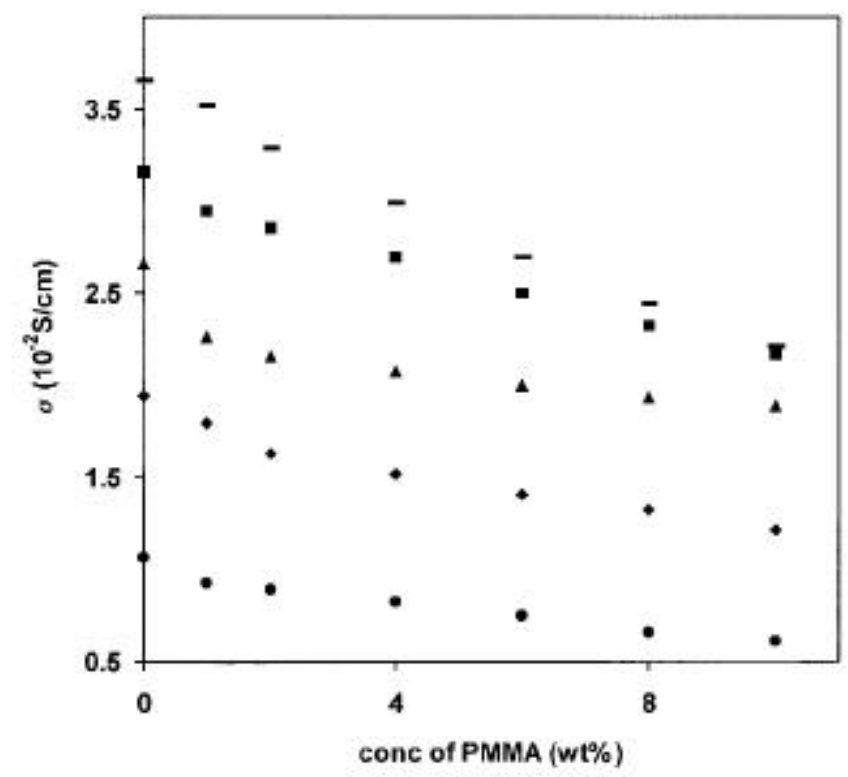

Figure 5. Conductivity as a function of PMMA concentration for polymer gel electrolytes containing $0 \cdot 1(\bullet), 0 \cdot 25(\bullet), 0.5$ $(\mathbf{\bullet}), 0.75(\mathbf{-})$ and $1 \mathrm{M}(-) \mathrm{NH}_{4} \mathrm{CF}_{3} \mathrm{SO}_{3}$ in DMA. 
effect of polymer on the viscosity of electrolytes was also studied and fluidity $\left(\phi=\eta^{-1}\right)$ was calculated which is given by

$$
\phi=\left(e^{2} / 6 \pi r\right) n \sigma
$$

where $e$ is an electronic charge, $r$ the effective radius of the diffusing species, $n$ the number density of charge carriers and $\sigma$ is conductivity. The fluidity is directly proportional to the conductivity of the electrolytes. The variation of fluidity with PMMA concentration for gel electrolytes containing different concentrations of $\mathrm{NH}_{4} \mathrm{CF}_{3} \mathrm{SO}_{3}$ in DMA is given in figure 7. Fluidity has been found to decrease with PMMA concentrations and its comparison with conductivity results (given in figure 5) shows a close correlation and a decrease in fluidity has been found to result with a decrease in conductivity.

The conductivity and viscosity of polymer gel electrolytes obtained by adding $10 \mathrm{wt} \%$ PMMA to $1 \mathrm{M}$ solution of $\mathrm{NH}_{4} \mathrm{CF}_{3} \mathrm{SO}_{3}$ in DMA were also measured as a function of temperature and the variation of $\log$ conductivity and log fluidity with reciprocal temperature is given in figure 8. For comparison the variation of conductivity of liquid electrolytes ( $1 \mathrm{M} \mathrm{NH}_{4} \mathrm{CF}_{3} \mathrm{SO}_{3}$ in DMA) with temperature is also included in this figure. The conductivity of liquid and gel electrolytes increases with an increase in temperature and the variation for gel electrolytes is similar to that observed for the corresponding liquid electrolytes which suggests liquid-like behaviour of these gel electrolytes. The fluidity of gel electrolytes also increases with an increase in temperature and follows Arrhenius behaviour. Both fluidity and conductivity are directly related to each other and an increase in fluidity results in higher mobility which enhances the conductivity of the electrolytes.

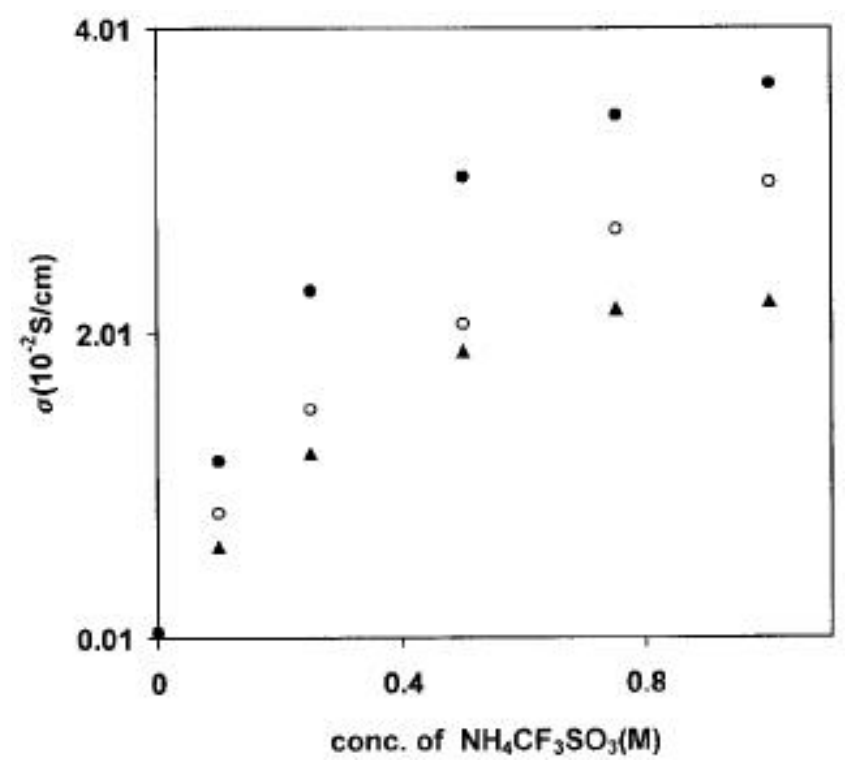

Figure 6. Conductivity as a function of $\mathrm{NH}_{4} \mathrm{CF}_{3} \mathrm{SO}_{3}$ concentration for gel electrolytes containing $0(\bullet), 4$ (o) and 10 (4) wt $\%$ PMMA.
The role of PMMA in these polymer gel electrolytes along with the possible interactions between salt, solvent and polymer was studied by FTIR spectroscopy and FTIR spectra of DMA (a), $\mathrm{NH}_{4} \mathrm{CF}_{3} \mathrm{SO}_{3}$ (b), liquid electrolyte containing $1 \mathrm{M} \mathrm{NH} \mathrm{CF}_{3} \mathrm{SO}_{3}$ in DMA (c) and the corresponding gel electrolytes containing $10 \mathrm{wt} \%$ PMMA (d) are given in figure 9. The spectra of $\mathrm{NH}_{4} \mathrm{CF}_{3} \mathrm{SO}_{3}$ show bands at 1251 and $764 \mathrm{~cm}^{-1}$ due to the symmetric and asymmetric stretch of $\mathrm{CF}_{3}^{-}$and bands at 1031 and $640 \mathrm{~cm}^{-1}$ due to the symmetric and asymmetric stretch of $\mathrm{SO}_{3}^{-}$,

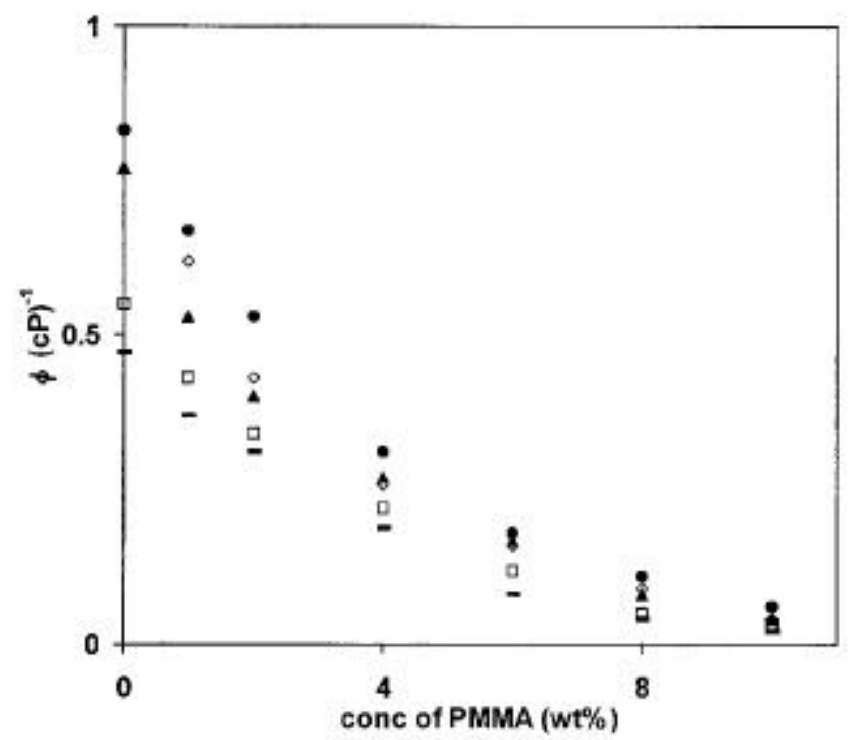

Figure 7. Variation of fluidity $(\phi)$ with PMMA concentration for gel electrolytes containing $0.1(\bullet), 0.25(\diamond), 0.5(\mathbf{\Delta}), 0.75$ $(\square)$ and $1 \mathrm{M}(-) \mathrm{NH}_{4} \mathrm{CF}_{3} \mathrm{SO}_{3}$ in DMA.

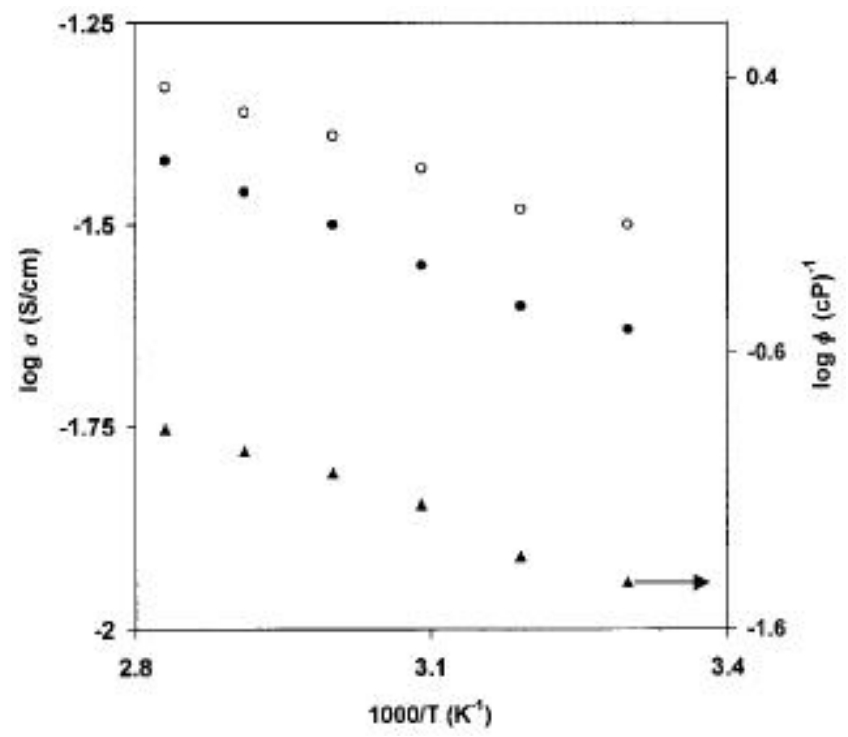

Figure 8. Variation of $\log \sigma$ with reciprocal temperature for liquid electrolyte (o) containing $1 \mathrm{M} \mathrm{NH}_{4} \mathrm{CF}_{3} \mathrm{SO}_{3}$ in DMA and $\log \sigma(\bullet)$ and $\log \phi(\mathbf{\Delta})$ of corresponding gel electrolytes containing $10 \mathrm{wt} \%$ PMMA. 


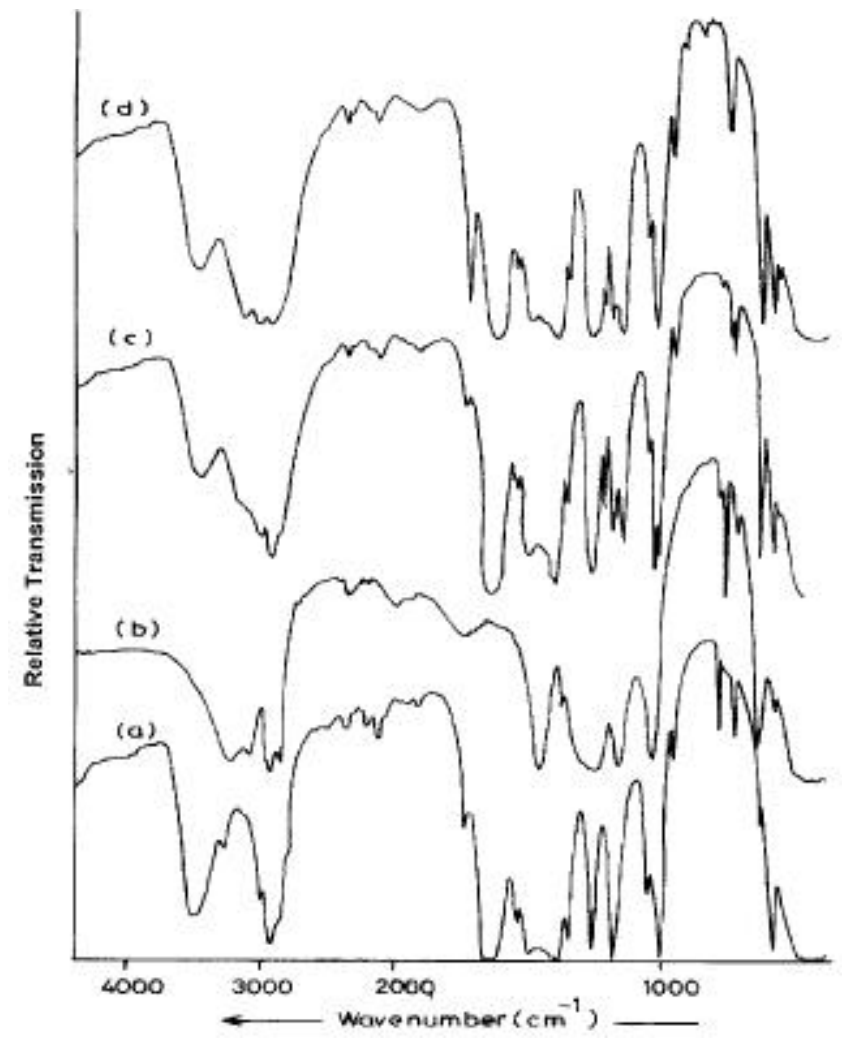

Figure 9. FTIR spectra of dimethylacetamide (a), ammonium triflate (b), liquid electrolyte containing $1 \mathrm{M} \mathrm{NH}_{4} \mathrm{CF}_{3} \mathrm{SO}_{3}$ in DMA (c) and the corresponding gel electrolytes containing $10 \mathrm{wt} \%$ PMMA (d).

respectively. The peak observed at $1456 \mathrm{~cm}^{-1}$ is due to $\mathrm{NH}_{4}^{+}$bending whereas peaks in the $3000-3200 \mathrm{~cm}^{-1}$ range are due to the symmetric and asymmetric stretching of $\mathrm{NH}_{4}^{+}$group. The spectra of DMA shows peaks at 1643 and $1549 \mathrm{~cm}^{-1}$ associated with the carbonyl group of DMA and symmetric and asymmetric stretching of $\mathrm{N}-\mathrm{H}$ (Silverstein and Webster 1997; Socrates 1998).

In the case of liquid electrolytes when $\mathrm{NH}_{4} \mathrm{CF}_{3} \mathrm{SO}_{3}$ is added to DMA, the $1643 \mathrm{~cm}^{-1}$ peak shifts to lower wavenumber side. The shifting of peak at $1643 \mathrm{~cm}^{-1}$ associated with carbonyl of DMA to lower wavenumber side suggests that interactions are taking place between the salt and the solvent. Also the peak observed at $1456 \mathrm{~cm}^{-1}$ which has been assigned to be due to $\mathrm{NH}_{4}^{+}$ bending disappears and this also suggests that there are some kind of interactions taking place between salt and solvent. The shifting of 1251 and $764 \mathrm{~cm}^{-1}$ peaks to higher wavenumber side could be due to the presence of ion aggregates, which was also reflected in the conductivity behaviour as given in figures 1 and 3 . The addition of PMMA to liquid electrolytes results in the broadening of peaks around $3000 \mathrm{~cm}^{-1}$ and could be due to the overlapping of $\mathrm{C}-\mathrm{H}$ band of PMMA and $\mathrm{N}-\mathrm{H}$ band of DMA. No other major change in the spectra has been observed with PMMA addition, which suggests the absence of any interaction between polymer and liquid electrolytes. This shows that PMMA plays a passive role and mainly acts as a stiffener which is consistent with the results obtained from conductivity studies on these electrolytes.

\section{Conclusions}

Nonaqueous polymer gel electrolytes containing $\mathrm{NH}_{4}$ $\mathrm{CF}_{3} \mathrm{SO}_{3}$ with high conductivity of $\sim 10^{-2} \mathrm{~S} / \mathrm{cm}$ at $25^{\circ} \mathrm{C}$ have been synthesized. The increase in free $\mathrm{H}^{+}$ion concentration with the addition of salt has been studied by $\mathrm{pH}$ measurements. The variation of conductivity and viscosity with salt concentration, polymer concentration and temperature has been studied and the decrease in conductivity with PMMA concentration has been found to be closely related to a decrease in the fluidity of the electrolytes. FTIR studies show the absence of an interaction between PMMA and liquid electrolyte which suggests that PMMA plays the role of a stiffener in these gel electrolytes.

\section{Acknowledgement}

The authors are thankful to CSIR for financial help in the form of a research scheme No. 03(0962)02/EMR-II.

\section{References}

Abraham K M and Alamgir M 1990 J. Electrochem. Soc. 137 1657

Ansari S M, Browdwin M, Stainer M, Druger S D, Ratner M A and Shriver D F 1985 Solid State Ionics 17101

Bohnke O, Frand G, Rezrazi M, Rousselot C and Truche C 1993a Solid State Ionics 66105

Bohnke O, Frand G, Rezrazi M, Rousselot C and Truche C 1993b Solid State Ionics 6697

Chandra S, Maurya K K and Hashmi S A 1990 in Recent advances in fast ion conducting materials and devices (eds) B V R Chowdari, Q Liu and L Chen (Singapore: World Scientific) p. 549

Colomban P (ed.) 1992 Proton conductors: solids, membranes and gels-materials and devices (Cambridge: Cambridge University Press)

Cronin J P, Gudgel T J, Kennedy S R, Agrawal A and Uhlmann D R 1999 Mater. Res. 21

Daniel M F, Desbat B and Lassegues J C 1988 Solid State Ionics 28-30 632

Feuillade G and Perche Ph 1975 J. Appl. Electrochem. 563

Kumar M and Sekhon S S 2002 Eur. Polym. J. 381297

Laforgue A, Simon P, Sarrazin C and Fauvarque J $1999 \mathrm{~J}$. Power Sources 80142

Oradd G, Furlani M and Ferry A 2000 Solid State Ionics 136137457

Paoli D R, Nogueira A F, Machado D A and Longo C 2001 Electrochim. Acta 464243

Perry M L and Fuller T F 2002 J. Electrochem. Soc. 149 S59 
Prusinowska D, Wieczorek W, Wycislik H and Przyluski J 1994 Solid State Ionics 72152

Ratner M A 1987 in Polymer electrolyte reviews (eds) J R MacCallum and C A Vincent (London: Elsevier Applied Science) Vol. 1 p. 173

Sekhon S S, Pradeep and Agnihotry S A 1998 in Solid state ionics: Science and Technology (eds) B V R Chowdari et al (Singapore: World Scientific) p. 217

Silverstein R M and Webster F X 1997 Spectroscopic identification of organic compounds (New York: John Wiley and Sons) 6th ed., Ch. 4
Slade R C T, Hardwick A and Dickens P G 1983 Solid State Ionics 9-10 1093

Socrates G 1998 Infrared and Raman characteristic group frequencies: Tables and charts (London: Wiley Science) 2nd ed.

Southall J P, Hubbard H V St A, Johnston S F, Rogers V, Davies G R, McIntyre J E and Ward I M 1996 Solid State Ionics 8551

Stainer M, Hardy L C, Whitmore D H and Shriver D F $1984 \mathrm{~J}$. Electrochem. Soc. 131784

Tsuchida E, Ohno H and Tsunemi K 1983 Electrochim. Acta 28591 Webber A 1991 J. Electrochem. Soc. 1382586 